\title{
Excretory calcinosis: a new fatal disease of wild American lobsters Homarus americanus
}

\author{
Alistair D. M. Dove ${ }^{1, *}$, Carl LoBue ${ }^{2}$, Paul Bowser ${ }^{3}$, Mark Powell ${ }^{4}$ \\ ${ }^{1}$ Cornell University College of Veterinary Medicine, c/o Marine Sciences Research Center, Stony Brook University, \\ Stony Brook, New York 11794, USA \\ ${ }^{2}$ New York Department of Environmental Conservation, 205 Belle Mead Road, East Setauket, New York 11733, USA \\ ${ }^{3}$ Department of Microbiology and Immunology, Cornell University College of Veterinary Medicine, Ithaca, New York 14853, USA \\ ${ }^{4}$ School of Aquaculture, Tasmanian Aquaculture and Fisheries Institute, University of Tasmania, Locked Bag 1-370, \\ Launceston, Tasmania 7250, Australia
}

\begin{abstract}
A significant number of moribund and dead lobsters Homarus americanus were reported to New York state authorities by lobster fishers in Long Island Sound (LIS) during the summer of 2002. Morbid lobsters were characterised by an orange discolouration of the abdomen, lethargy, an excess of epibionts and poor post-capture survival. On necropsy, severe extensive multifocal or diffuse mineralised granulomatous inflammation of the gills and antennal glands was the most striking pathology. In the gills, granulomas often occluded the lumen of filaments, resulting in congestion, ischemia and coagulative necrosis of gill tissues. In the antennal glands, granulomas were concentrated along the border between the coelomosac and labyrinth. No significant pathogens were recovered from diseased individuals. In prechronic individuals, however, it was evident that granulomas were focused around calcium carbonate (aragonite) crystals. This disease may result from anomalously high sea-bottom temperatures in LIS $\left(\sim 23^{\circ} \mathrm{C}\right)$ during the summer of 2002 and associated disruptions of the calcium chemistry of lobsters in favour of deposition of minerals in soft tissues. The ultimate cause of death of affected lobsters is probably respiratory failure due to reduced effective surface area of the gills, exacerbated by hypermetabolic temperatures and an abundance of epibionts.
\end{abstract}

KEY WORDS: Lobster · Homarus · Granuloma · Calcium · Aragonite · Calculus · Calcinosis · Temperature -Resale or republication not permitted without written consent of the publisher

\section{INTRODUCTION}

Throughout the 1990s, American lobsters Homarus americanus were the most valuable single-species marine fishery in New York State. The fishery is concentrated in Long Island Sound (LIS), bounded on the south by Long Island and on the north by the Connecticut coastline. During the 1990s, the standing stock of lobsters increased greatly in LIS, with a concomitant increase in commercial landings, peaking at $5000000 \mathrm{~kg}$ in 1997 (C. LoBue et al. unpubl.data).

In the autumn of 1999, the industry was decimated by a major lobster mass mortality event, during which perhaps $90 \%$ of lobsters from the western third of LIS died. The 1999 mortality event was concurrent with a high bottom-temperature anomaly and severe hypoxia in the waters of western LIS. The causes of the mortality event may have included the temperature and hypoxia themselves, or infection of stressed lobsters by Paramoeba species (Russell et al. 2000), a combination of these factors, or a cause not yet identified.

At the beginning of August 2002, significant occurrences of moribund and dead lobsters were reported to New York State Department of Environmental Conservation (NYSDEC) officers by lobster fishers. These initial reports were from the border between central LIS and eastern LIS, due south of Branford, Connecticut; but the disease was reported from as far west as 
Oyster Bay. This paper reports a novel, apparently noninfectious, granulomatous disease of lobsters, excretory calcinosis, associated with this mortality event.

\section{MATERIALS AND METHODS}

Collection of lobsters. Moribund lobsters were submitted for laboratory evaluation by biologists from NYSDEC after collection from lobster fishers. The sites from which the lobsters originated are shown in Fig. 1. Lobsters were initially captured in standard commercial lobster traps.

Necropsy. The lobsters were sexed based on location of the genital pores and modification of the first pleopod in males, then euthanased by rapid refrigeration in ice brine followed by exsanguination, after severing the body at the abdomino-cephalothoracic junction. The external body surfaces were thoroughly examined for shell disease or other external lesions. Haemolymph was withdrawn from the dorsal haemal sinus or the abdominal haemal sinus using a $3 \mathrm{~cm}^{3}$ syringe and 25-gauge needle and added to a $4 \mathrm{ml}$ Vacutainer (Becton Dickinson) blood-collection tube with $1 \mathrm{ml}$ of $3.8 \%$-buffered sodium citrate anticoagulant for later use in microbial culture. Some haemolymph was set aside in the syringe for qualitative observation of approximate clotting time. The cephalothoracic carapace was cut down the dorsal midline and both sides broken away to reveal the gills and visceral mass. A gill biopsy consisting of several branches was examined under the dissecting microscope, and any abnormal trichobranch filaments were subsequently examined under the compound microscope. Fresh squash preparations were also made for all visceral organs: heart, hepatopancreas, antennal gland, intestine, gonad, musculature, shell epithelium and ventral nerve cord. Fresh squash preparations were also made for the abdominal musculature,

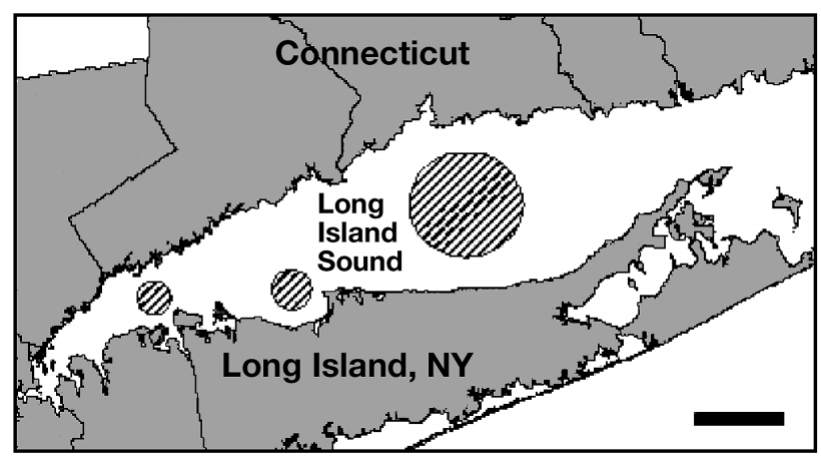

Fig. 1. Long Island Sound. Hatched circles: sites from which calcinotic lobsters Homarus americanus were collected. Scale bar $=\sim 10$ nautical miles abdominal nerve cord and rectum. Grossly abnormal tissues observed on necropsy were photographed with a Nikon CoolPix 995 digital camera (Nikon USA).

Microbiology. For bacteriological culture, approximately $0.5 \mathrm{ml}$ of haemolymph was spread using a sterile cell-spreader on Petri dishes containing 1 of media: malt-yeast agar with marine salts and tryptic soy agar with $5 \%$ sheep blood. One plate each was incubated at each of 15 and $30^{\circ} \mathrm{C}$. Isolates were identified to species using a Biolog ${ }^{\circledR}$ system.

Histology. Biopsies from the gills, hepatopancreas, antennal glands, intestine, musculature and ventral nerve cord, were fixed in either $10 \%$ neutral-buffered formalin or Davidson's alcohol formalin acetic acid mixture (Luna 1968), for later histological processing. All tissues were embedded in paraffin, sectioned at $6 \mu \mathrm{m}$ and stained with haematoxylin and eosin (Luna 1968). In addition, the following stains were applied to representative sections: Grocott's methionine silver (GMS) stain for fungal infections, Gram stain for bacteria, Ziehl-Neelsen (ZN) acid fast stain for acid-fast bacteria, Prussian blue stain for iron deposits, and von Kossa stain for calcification (Luna 1968).

Fresh tissues and histological sections were examined on a Nikon TE2000 microscope using brightfield, darkfield, DIC (Differential Interference Contrast) and fluorescence illumination. Images were captured using an Insight digital camera and post-processed in ImagePro Plus (Media Cybernetics) and Adobe Photoshop 5.5 (Adobe Systems).

\section{RESULTS}

We examined 18 lobsters, 16 of which were affected with the disease and 2 not. In addition, 1 spider crab Libinia emarginata, 1 rock crab Cancer irroratus, 1 hermit crab Pagurus sp. and 1 blue crab Callinectes sapidus were examined. It should be noted that no overtly diseased individuals of any other crustacean species had been reported. At necropsy, the disease syndrome was not observed in any other species. No associations with disease were detected based on sex of lobsters; there were more female than male lobsters in the sample, but this ratio was in proportion to the population structure at the sampling site.

\section{Necropsy}

Affected lobsters displayed a consistent set of gross signs of varying degrees of severity. All lobsters appeared to be in late intermoult or premoult phases ('hard-shelled' lobsters), although pleopod staging was not used to quantify moult stage. Most lobsters exam- 
ined were severely lethargic or moribund. They had distinctly orange abdomens, as observed through the translucent abdominal cuticle. Haemolymph samples drawn from either the dorsal haemal sinus or the ventral abdominal sinus were similarly orange and displayed severe coagulopathy compared to normal lobster haemolymph, which tends to clot firmly within seconds to minutes. In contrast, haemolymph samples from affected lobsters tended to clot slowly (within hours), poorly, or not at all.

The gills of affected lobsters typically had an abundance of epibionts, particularly the filamentous bacterium Leucothrix sp., the bryozoan Triticella sp., the ecotcommensal polychaete Histriobdella homari and an unidentified peritrichous ciliate. The lumina of gill trichobranch filaments frequently appeared congested. Microscopically, an abundance of yellow to brown granulomas was present within the gill filaments, often occluding the lumen and causing ischemia. At the gross level, ischemia was observed as an opacity of the areas distal to the blockage. The proportion of affected filaments varied, but exceeded $80 \%$ in many cases, resulting in a severe reduction in the available respiratory surface. At times the entire distal portion of a gill branch was observed to be completely ischemic, resulting in $100 \%$ loss of respiratory function in those areas.

The antennal glands were atypical in colour, appearing brown instead of the usual green, and frequently of a granular or patchy appearance at the gross level.

Most other tissues appeared normal, except for very occasional large granulomas in the hepatopancreas. These were of a very different nature from those in the gills and antennal glands in that they were neither mineralised, nor spheric/polyspheric, and were significantly larger than the mineralised microgranulomas in the antennal glands and gills. We interpreted these granulomas as the probable result of idiopathic atrophy of hepatopancreatic tubules. They are not likely to be related to calcinosis, since they are also observed in otherwise healthy lobsters. The musculature appeared distinctly orange, but this was apparently due to the discolouration of the haemolymph that perfuses the muscles rather than to any change in the musculature itself.

\section{Microbiology}

Bacterial growth was absent or scant on both malt-yeast agar, and tryptic soy agar and the amount and type of growth did not appear to differ significantly between affected and unaffected individuals. Isolates from 1 lobster were identified to species and showed the presence of Halvnia alvei, Listonella anguillarum and a Salmonella Group B isolate. Given the minimal growth observed and the absence of growth in many affected individuals, we consider these infections to be potential contaminants from ubiquitous populations of marine bacteria and unlikely to be associated with the calcinosis observed. This conclusion is consistent with the failure to detect bacteria within the lesions themselves by any staining technique.

\section{Histopathology}

Microscopic examination of the gills and antennal gland revealed the presence of severe extensive multifocal or diffuse granulomatous inflammation involving dense spherical or polyspherical haemocytic granulomas. The granulomas were ZN-negative, GMSnegative and Prussian blue-negative, indicating that they were not caused by acid-fast bacteria, fungi or iron deposits, respectively. The lesions were Gramindeterminate or refractory to Gram stain, and no bacteria were observed within them. They were von Kossa-positive, however, indicating the presence of mineralised material within their matrices.

Where present in the gills, the granulomas often caused congestion or blockage in trichobranch filaments, resulting in ischemia and coagulative necrosis of the distal portion of affected filaments (Fig. 2E,F). In the main gill branch, the haemolymph sinuses were congested and showed total depletion of reserve inclusion cells. These cells are primarily involved in energy storage and their absence from affected individuals indicated energetic exhaustion.

In the antennal glands, the granulomas were concentrated along the margin between the primary filtration zone of the gland (coelomosac) and the secondary selective reabsorbtion zone (labyrinth) (Fig 2G,H). In the region of greatest granuloma density, there was disruption of the tissue architecture, an abundance of pyknotic nuclei in the gland cells and multifocal necrotic areas.

\section{Prechronic phase}

We observed 2 lobsters in the prechronic phase of the disease. In the prechronic phase, naked calcium carbonate crystals (aragonite) were observed in addition to granulomas at various levels of development. Naked crystals were seen primarily in the tissues of the antennal gland and, occasionally, the gills. These crystals were 5 to $50 \mu \mathrm{m}$ in diameter, spheroid, clear to golden-yellow or yellow-brown in colour, and with a distinctive radial striation pattern and a highly refrin- 

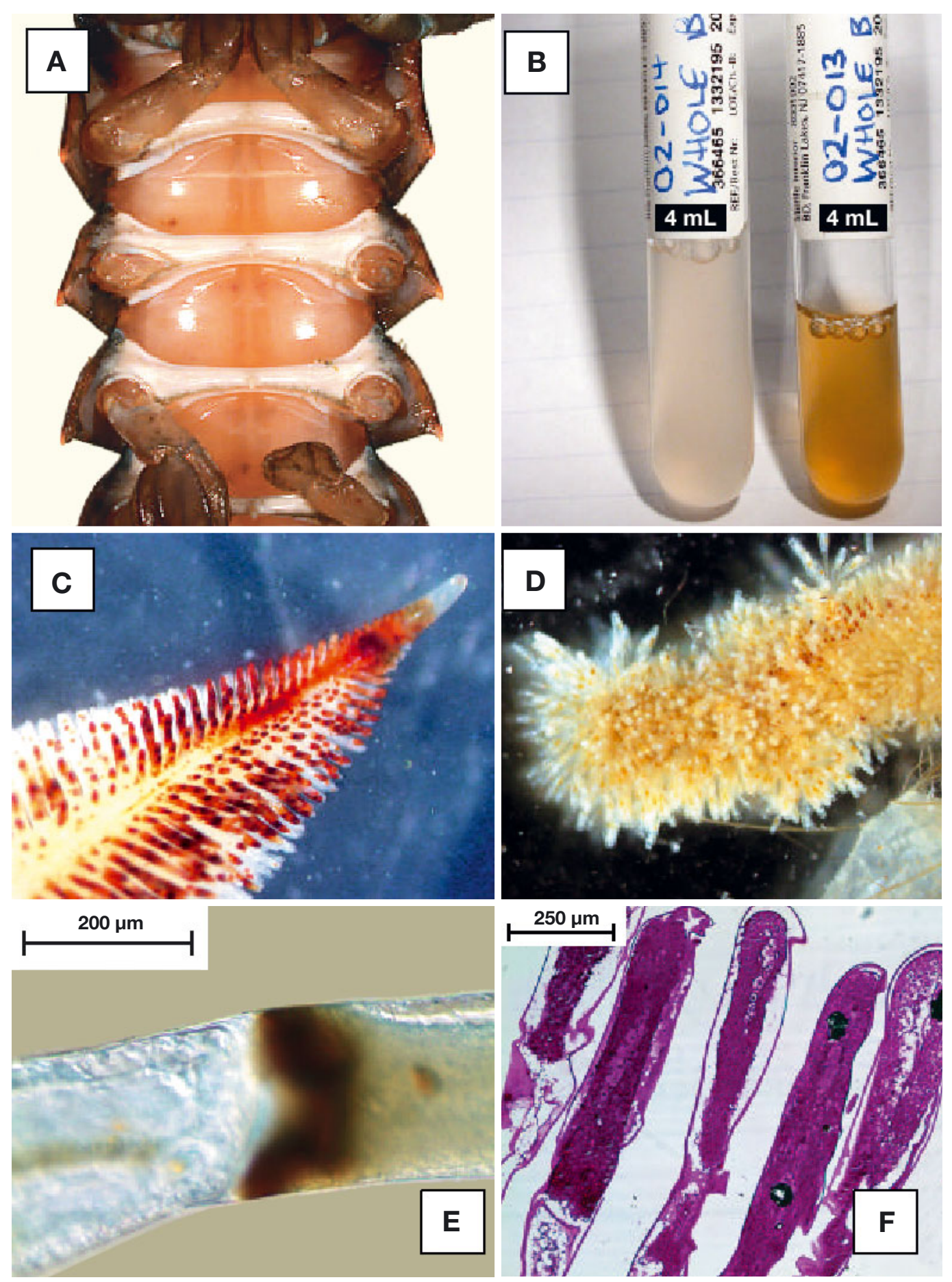

Fig. 2. Homarus americanus. Affected lobster tissues. (A) Abdomen of calcinotic lobster showing orange colouration (pleopods removed); (B) haemolymph of unaffected (left) and affected (right) lobsters, with affected lobster showing orange colouration; (C) gill branch of affected lobster, showing extensive ischemia of trichobranch filaments; (D) dense growth of bryozoan Triticella sp. on gills of calcinotic lobster; (E) ischemic gill filament caused by blockage due to calculus; (F) histological section of gill filaments showing coagulative necrosis and embedded von Kossa-positive (black) mineralized granulomas (von Kossa stain); (G) histological section of antennal gland showing concentration of lesions along margin of 2 portions of gland (see 'Results') (H\&E stain); (H) histological section of granulomas in antennal gland showing polyspheric nature of granulomas and refractory crys talline material (golden brown); (I) naked aragonite crystal in fresh squash of antennal gland tissue, showing golden brown colour, spheroid shape and radial striations; $(\mathrm{J})$ aragonite crystal involved in granuloma: on left, bright field illumination, and crystal is not visible; on right, darkfield illumination crystal visible and strongly birefringent (arrow) 

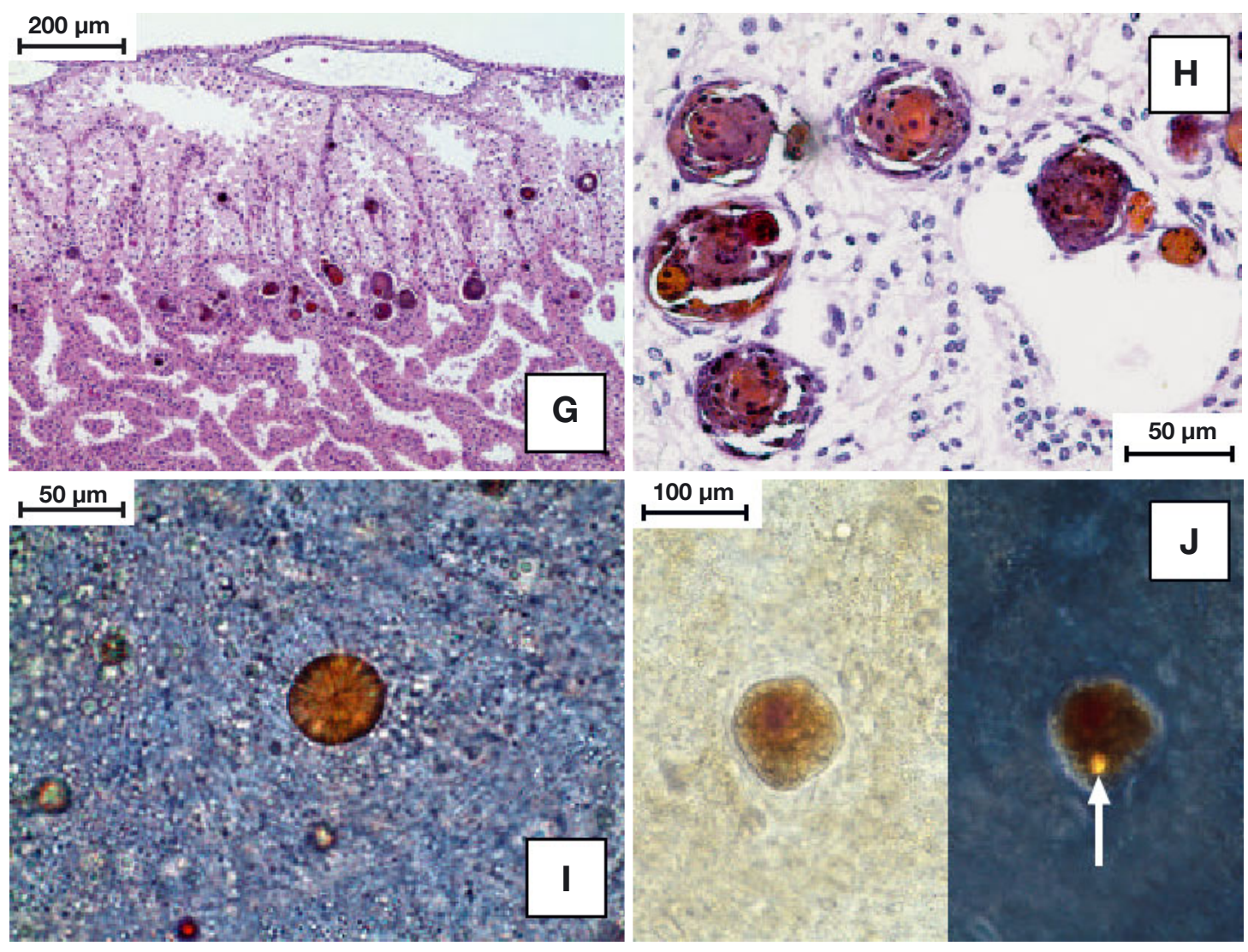

Fig. 2 (continued)

gent appearance under darkfield illumination. A small proportion of crystals were twinned, a condition where 2 crystals grow into each other. Naked crystals showed no autofluorescence in the green or UV wavelengths, whereas granulomas fluoresced strongly in both these spectra. Differential fluorescence may in future prove useful for staging the disease.

\section{DISCUSSION}

The fatal disease observed in LIS lobsters examined during the mortality event of summer 2002 was an excretory calcinosis characterised by the formation of aragonite calculi in their 2 main excretory organs, the gills and antennal glands, and their subsequent involvement in granulomatous inflammation. We are not aware of any published reports describing a similar lethal calcinosis in LIS lobsters from the 1999 mortality event or from any other lobster population. The causes of the formation of the calculi and the subsequent formation of the mineralised haemocytic granulomas have not yet been determined. We hypothesise that crystal deposition occurs due to the disruption of calcium regulation mechanisms in the lobster as a result of exposure to chronically-elevated sea-bottom temperatures. This process may be accompanied by changes in the carbonate-buffering chemistry of the haemolymph, perhaps also due to changes in temperature, blood $\mathrm{pH}$ or dissolved gas concentrations.

The calcium budget of lobsters is highly dynamic, and is tightly coupled to their moult cycle, growth and to environmental conditions (Zhuang \& Ahearn 1996, 1998, Ahearn et al. 1999, Klein \& Ahearn 1999, Wheatly 1999, Flik \& Haond 2000). These mechanisms are normally used to regulate intra- and extracellular calcium concentrations and to rapidly translocate calcium across epithelia during the moulting cycle (Wheatly 1999). During the cycle, mineral calcium is usually stored in intracellular phosphate-storage granules and in extracellular gastroliths in the stomach (Ahearn et al. 1999, Wheatly 1999). Epithelia known to have an abundance of calcium-regulation channels occur in the gills, the hepatopancreas, the antennal glands and the shell epithelium. While there are common types of calcium channels between these epithelia (such as those in the basolateral membranes: Ahearn et al. 1999), it has been noted that there may be tissuespecific channels and discrete genetic regulation mechanisms, the exact nature of which has not yet 
been determined in vivo (Wheatly 1999). Differential distribution of different calcium-regulation channels may, in part, explain the distribution of calculi in lobster tissues.

Calcium can also play a role in the clotting cascade of lobster haemolymph. Calcium mediates the release of cytosolic contents from hyalinocytes and semigranulocytes in the spiny lobster Panulirus japonicus, a process that is essential for clotting (Aono \& Mori 2002). It is reasonable to expect that a similar process operates for Homarus spp. The ability to clot is reduced or absent in the haemolymph of lobsters affected by excretory calcinosis. This condition may result from disruption of clotting cascades through sequestration of haemolymph calcium to calculi.

Lobsters are adapted to widely fluctuating calcium levels and are equipped with mechanisms for rapid movement, conjugation and storage of large amounts of mineral calcium. Consequently, the existence of a calcinosis disease in lobsters is somewhat puzzling. In our opinion, the key may lie in the carbonate conjugate. Calcium can be stored in circulating granules in the crustacean haemolymph (Sparkes \& Greenaway 1984, Greenaway \& Farrelly 1991) or in intracellular granules (Greenaway \& Farrelly 1991), but these deposits are usually calcium sulphate or phosphate. In the present case, the calculi appear to be primarily calcium carbonate, suggesting that the role of carbonate needs to be investigated in order to understand the condition.

Lobsters use a balance of carbonate and bicarbonate ions as a method for buffering their haemolymph $\mathrm{pH}$ within a narrow range (McMahon 1995) and as a source of anionic conjugates for aragonite deposition in the shell. The buffering process is complex, and has not been fully elucidated (Henry \& Wheatly 1992). Interestingly, some parts of the bicarbonate buffering system use the same $\mathrm{Na}^{+} / \mathrm{H}^{+}$antiporter membrane proteins as the calcium regulation mechanisms, suggesting that these channels may play a key role in the disease process.

In the gills and antennal gland, crystals become the focus of haemocyte aggregation and granuloma formation. Amorphous mineralised material becomes incorporated in the growing lesion, and the original crystal becomes obliterated. Exactly why aragonite crystals would be immunogenic is unclear, given that aragonite is an integral part of the exoskeleton of the lobster. It may represent a tissue-specific response, given the ectopic location of the crystals. Lobsters in the earliest phase of the disease have calculi and granulomas predominantly in the antennal glands, with little branchial involvement. The converse situation of branchial involvement with minimal antennal gland involvement was not observed. We interpret these data to indicate that the condition first manifests in the antennal gland, and only involves the gills in more severe cases. The capture or formation of calculi in the gills is consistent with the findings of Martin et al. (2000) that loose aggregations of haemocytes sequester foreign bodies in the gills, where they form spherical nodules. The trichobranch structure of the lobster gill, as opposed to the lamellate gills of crabs and other decapods, makes them particularly susceptible to blockage by calculi, with resulting ischemia and necrosis. Ischemia of the gills results in a major reduction in surface area for gas exchange which, in turn, probably causes severe respiratory stress and ultimately death by asphyxiation. This process may be exacerbated by the abundance of epibionts that appear to be associated with the gills of lethargic, calcinotic lobsters.

The precise etiology of excretory calcinosis in lobsters requires further investigation. Alternatives to the mechanism proposed above could also explain the onset of disease. The heavy-metal cadmium, for example, can competitively interfere with regulation of calcium in most animal cells (Verbost et al. 1989, Schoenmakers et al. 1992). A role for cadmium or other heavy-metals cannot be excluded at this time. Similarly, viral agents have not been excluded and the possibility remains that bacteria are responsible for the condition, despite the failure to culture significant pathogens from the haemolymph of affected individuals.

Despite the multiple potential etiologies for excretory calcinosis in lobsters, there is a strong correlation between the disease and high temperatures in LIS bottom waters. The average LIS-wide bottom-water temperature of LIS in summer 2002 was approximately $21^{\circ} \mathrm{C}$ (P. Stacey, Connecticut Department of Environmental Protection, pers. comm.), which is above the accepted upper thermal limit of $20^{\circ} \mathrm{C}$ for wild lobsters (Lawton \& Lavalli 1995) and is one of the higher averages on record. Many areas of LIS had much higher averages and extended periods of temperatures above $23^{\circ} \mathrm{C}$. Even the deepest parts of LIS, to which lobsters usually retreat during times of higher temperature in shallower waters, displayed similar temperatures, meaning that the lobsters had no refugium. At these temperatures, and with gills compromised by calcinosis and epibionts, even dissolved oxygen levels of $3 \mathrm{mg} \mathrm{l}^{-1}$ or more may be insufficient to supply the respiratory demands of the lobster.

An assessment of the severity of the 2002 lobster mortality event is hampered by the bias inherent in trap-sampling. Calcinotic lobsters are lethargic and show signs of energetic exhaustion, and would therefore be less likely than healthy lobsters to enter traps in search of food. Trawl-sampling in the affected areas would be more objective, but would not sample lob- 
sters in their burrows and would be difficult to carry out because of the high spatial density of trap gear deployed on the bottom of LIS. Our casual observations during 1 collection aboard a lobster boat and during 1 trawl survey suggest a field prevalence of perhaps $30 \%$ of captured lobsters affected, with no observable size or gender bias. Without a better method of assessing field mortality and accounting for morbidity and mortality in burrows (which is likely to be high), accurate assessment remains elusive.

Elevated temperature was correlated with the major LIS lobster mortality event of 1999, in which calcinosis was not observed. Other lobster mortality events in 1998 and 1990 also correlated with anomalously warm years, although the proximate causes of those events were not determined (C. LoBue et al. unpubl. data). The coincidence of the 2 best-investigated lobster mortality events (1999 and 2002) with 2 of the most severe bottom-temperature anomalies yet recorded for LIS emphasises the importance of investigating the effects of temperature on the long-term survival of the lobster in LIS waters.

Acknowledgements. We appreciate the assistance of P. Locicero, J. Powers and the Long Island lobster fishers in collecting sick lobsters. The Connecticut Department of Environmental Protection kindly provided temperature data for LIS. A.D. appreciates discussions with R. Wilson, M. Wheatly, S. Arnott, A. McElroy and R. Cerrato.

\section{LITERATURE CITED}

Ahearn GA, Duerr JM, Zhuang Z, Brown RJ, Aslamkhan A, Kim K, Killebrew DA (1999) Ion transport processes of crustacean epithelial cells. Physiol Biochem Zool 72:1-18

Aono H, Mori K (2002) Interaction between hemocytes and plasma is necessary for hemolymph coagulation in the spiny lobster, Panulirus japonicus. Comp Biochem Physiol A 113:301-305

Flik G, Haond C (2000) $\mathrm{Na}(+)$ and $\mathrm{Ca}(2+)$ pumps in the gills, epipodites and branchiostegites of the european lobster Homarus gammarus: effects of dilute sea water. J Exp Biol 203:213-220

Greenaway P, Farrelly C (1991) Trans-epidermal transport and

Editorial responsibility: Timothy Flegel,

Bangkok, Thailand storage of calcium in Holthusiana transversa (Brachyura, Sundathelpusidae) during premoult. Acta Zool 72:29-40

Henry RP, Wheatly MG (1992) Interaction of respiration, ion regulation and acid-base regulation in the everyday life of aquatic crustaceans. Am Zool 32:47-416

Klein MJ, Ahearn GA (1999) Calcium transport mechanisms of crustacean hepatopancreatic mitochondria. J Exp Zool 283:147-159

Lawton P, Lavalli KL (1995) Postlarval, juvenile, adolescent and adult ecology. In: Factor JR (ed) The biology of the lobster Homarus americanus. Academic Press, San Diego, p 47-88

Luna LG (1968) Manual of histological staining of the Armed Forces Institute of Pathology. McGraw-Hill, New York

Martin GG, Quintero M, Quigley M, Khosrovian H (2000) Elimination of sequestered material from the gills of decapod crustaceans. J Crustac Biol 20:209-217

McMahon BR (1995) The physiology of gas exchange, circulation, ion regulation, and nitrogenous excretion: an integrative approach. In: Factor JR (ed) The biology of the lobster Homarus americanus. Academic Press, San Diego, p 497-517

Russell S, Hobbie K, Burrage T, Koerting C, DeGuise S, Frasca S Jr, French RA (2000) Identification of a protozoon parasite in the American lobster Homarus americanus. J Shellfish Res 19:581

Schoenmakers TJM, Klaren PHM, Flik G, Lock RAC, Pang PKT, Bonga SEW (1992) Actions of cadmium on basolateral plasma membrane proteins involved in caclium uptake by fish intestine. J Membr Biol 127:161-172

Scott-Fordsmand JJ, Depledge MH (1997) Changes in the tissue concentrations and contents of calcium, copper and zinc in the shore crab Carcinus maenas (L) (Crustacea: Decapoda) during the moult cycle and following copper exposure during ecdysis. Mar Environ Res 44:397-414

Sparkes S, Greenaway P (1984) The hemolymph as a storage site for cuticular ions during premoult in the freshwater land crab Holthusiana transversa. J Exp Biol 113:43-48

Verbost PM, Flik G, Pang PKT, Lock RAC, Bonga SEW (1989) Cadmium inhibition of the erythrocyte Ca2+ pump-a molecular interpretation. J Biol Chem 264:5613-5615

Wheatly MG (1999) Calcium homeostasis in Crustacea: the evolving role of branchial, renal, digestive and hypodermal epithelia. J Exp Zool 283:620-640

Zhuang Z, Ahearn G (1996) $\mathrm{Ca}^{2+}$ transport processes of lobster hepatopancreatic brush-border membrane vesicles. J Exp Biol 199:1195-1208

Zhuang Z, Ahearn GA (1998) Energized $\mathrm{Ca}^{2+}$ transport by hepatopancreatic basolateral plasma membranes of Homarus americanus. J Exp Biol 201:211-220

Submitted: December 2, 2002; Accepted: September 19, 2003 Proofs received from author(s): February 2, 2004 